\title{
COOPERAÇÃO ENTRE PROFESSORES: A FORMAÇÃO INICIAL DEVE PRECEDER AS PRÁTICAS?
}

\author{
MONICA GATHER THURLER \\ Faculdade de Psicologia e de Ciências da Educação, Universidade de Genebra \\ monica.gather-thurler@pe.unige.ch \\ PHILIPPE PERRENOUD \\ Faculdade de Psicologia e de Ciências da Educação, Universidade de Genebra \\ philippe.perrenoud@pse.unige.ch \\ Tradução: Neide Luzia de Rezende
}

\begin{abstract}
RESUMO
A cooperação entre profissionais está mais presente no discurso do que nas práticas. $\mathrm{Na}$ formação inicial será preciso ater-se ao estado atual da profissão, antecipar suas evoluções previsiveis e tentar orientá-las? As práticas de referência na formação profissional são diversas, têm evoluído muito e estão sujeitas a controvérsias. No entanto, se a cooperação apresenta-se como uma necessidade para a formação, outras questões se colocam. Que identidade, que relação com os outros e com a organização, que competências, que conhecimentos desenvolver para além do entusiasmo com o tema ou de sua obrigatoriedade, uma vez que essas posturas só produziriam efeitos negativos?

FORMAÇÃO DE PROFESSORES - PROFESSORES - FRANÇA - FORMAÇÃO PROFISSIONAL
\end{abstract}

\begin{abstract}
ABSRACT
COOPERATION AMONG TEACHERS: SHOULD INITIAL TEACHER TRAINING ANTICIPATE PRACTICES? Cooperation among professionals ends up being more mentioned
\end{abstract}

Este artigo foi originalmente publicado em francês em Recherche et Formation, n.49, p. I- I4, 2005, com o título "Coopération entre enseignants: la formation initiale doit-elle devancer les pratiques?". 
in statements than put into practice. Is it necessary to follow the current status of the profession, anticipate its expected evolution and try to guide it during initial teacher training? Professional teacher training includes reference practices of various types, but they have evolved a lot and are subject to controversies. However, if cooperation is regarded as something that is needed for teacher training, other issues arise. What identity, what relationship with others and with the organization, what competences, what knowledge to develop beyond keen enthusiasm with the theme or its obligatoriness, since these postures would only produce negative effects? TEACHER EDUCATION - TEACHERS - FRANCE - VOCATIONAL TRAINING

A cooperação entre profissionais dialoga com a concepção da transposição didática na formação dos professores. As práticas evoluem, o individualismo decresce, mas isso muitas vezes ocorre a partir de escolhas militantes ou em circunstâncias particulares como, por exemplo, no trabalho nas zonas e redes de educação prioritária na França. Os Institutos Universitários de Formação de Professores - IUFMs - franceses, ou seus equivalentes em outros países, podem privilegiar as práticas emergentes, arriscando lançar os professores iniciantes em estabelecimentos escolares que não trabalham de modo cooperativo. As instituições de formação inicial podem fazer a escolha inversa; relegar a aprendizagem da cooperação à iniciativa dos indivíduos ou da formação contínua, correndo o risco de colocar em outros estabelecimentos, onde existe forte cooperação, professores pouco entusiasmados e pouco capazes de trocas sobre suas práticas, com dificuldade de trabalhar em equipe ou em rede.

Essa escolha, política, deveria fundar-se sobre o estado das práticas. Mas nenhuma pesquisa pode prescindir de uma conceituação da cooperação e das evoluções culturais e estruturais do ofício de professor e do sistema educacional. Se a cooperação não estiver inscrita - conceitual e estruturalmente - numa organização do trabalho (ciclos, procedimentos pluridisciplinares e outras formas instituídas de ação coletiva), ela permanecerá como um modo de relação que depende muito do livre-arbítrio dos professores e do clima do estabelecimento.

Por meio desse exemplo, põe-se a questão da justa distância entre a reprodução de práticas tradicionais e a fuga na utopia.

É possível, quando se constrói um plano de formação, referir-se a uma imagem tão ideal quanto abstrata do ofício de professor. Às perguntas "O que é ensinar hoje? Como o ofício se apresentará amanhã?" são dadas respostas às vezes simples, consensuais e positivas. O ganho simbólico é inegável, mas a que preço? Formam-se professores para um ofício que não existe mais, nunca 
existiu ou, no melhor dos casos, representa uma pequena parcela da realidade. E se continua a trabalhar:

...no meio de estruturas de ontem com métodos de hoje para resolver problemas de amanhã, essencialmente com pessoas que realizaram, no meio de culturas de anteontem, essas estruturas de ontem e que jamais conhecerão o futuro de nosso trabalho. (Sprenger, 1992, p. 43, tradução, para o francês, M. Gather Thurler).

É verdade que, se quisermos fundamentar a formação inicial na realidade do ofício e de como ele evoluiu, as dificuldades logo aparecem: essa realidade é múltipla, controversa, difícil de circunscrever sem pesquisas precisas e almejadas pelos principais atores coletivos envolvidos. Pode-se discernir as tendências que guiam a evolução, mas elas não estão isentas de contradições e de impasses.

A didática habituou-nos à idéia de "práticas sociais de referência", em um movimento que busca essencialmente não aprisionar a transposição dos saberes. Em Línguas, Artes, Esporte, mas também em Ciências, Matemática, Geografia, não se ensinam só saberes; desenvolvem-se práticas, começando pela leitura e pela produção de textos. Isso traz para os organizadores de programas escolares um novo problema: enquanto os saberes a ensinar na escola têm porta-voz - nas associações científicas, nas universidades, nas academias e em outras instâncias autorizadas a "dizer o saber" -, não há nenhum equivalente para as práticas sociais e menos ainda para as mais emergentes. A diversidade é maior e a escolha de uma referência em detrimento das outras se mostra como é: arbitrária, orientada ideologicamente, favorecendo uma visão da prática - e do mundo - em vez de outra.

mesmo ocorre nas formações profissionais. A diversidade das referências é a regra. Todo ofício conhece diferentes condições para o seu exercício, mas ele é composto também pela coexistência de imagens diferentes, e com freqüência inconciliáveis, daquilo que deveria ser o ofício: dos passadistas e dos vanguardistas, dos defensores de uma corporação fechada e dos que ultrapassam fronteiras, dos fanáticos pelas tecnologias e dos adeptos da relação; imagens essas que constituem clivagens "clássicas" às quais se juntam aquelas que dizem respeito a só um ou outro ofício. 
O ensino não é exceção, ou então chega a ser pela enorme diversidade das referências possíveis. Isso é tão verdade que não poderíamos refletir isoladamente sobre a dimensão cooperativa do ofício de professor, já que ela representa apenas um componente de um imenso caleidoscópio cujos elementos se combinam e recombinam sem cessar, segundo as vivências, as prioridades do momento, o ambiente e as relações de poder entre os diversos atores envolvidos.

Talvez tenha existido um tempo em que a essência do ofício de professor era relativamente homogênea. Não há dúvida que ensinar no primeiro e segundo graus, no meio urbano, na periferia ou no campo, em bairros populares ou burgueses não era exatamente a mesma coisa. Mas em razão do estado de relativo consenso quanto aos valores e à normalização das formações, é viável imaginar uma certa unidade de concepção do ofício, com adaptações, ao mesmo tempo inevitáveis e desejáveis, à idade, ao nível, às aspirações dos alunos e aos conteúdos dos programas.

Hoje os motivos para tornar-se professor se diversificaram: incluindo desde a vocação humanitária até o trabalho pelo sustento; as origens sociais são heterogêneas: dos filhos da alta burguesia em declínio social aos filhos de operários em ascensão, passando pelas inumeráveis figuras da reprodução das classes médias; o casamento complicando singularmente a identificação social numa profissão fortemente feminizada. Nas nossas sociedades, o status dos professores tornou-se banal; estes não são nem de longe os únicos a praticar um ofício da área de humanas e de comunicação, mantêm-se no terciário em expansão e nas novas classes médias.

Existem claramente relações muito diferentes nesse ofício. A cena midiática opõe os guardiões da cultura, presos ao elitismo republicano, aos pedagogos fascinados pela centralidade das crianças. Essas oposições mascaram a relativa indiferença da grande massa de professores em relação a esses debates ideológicos. Claro que quando se trata de escarnecer de um ministro ou de bloquear uma reforma, uma divisão mais ampla se instala, os indiferentes escoIhem seu campo. No entanto, eles voltam rapidamente ao quotidiano.

Cada professor pode oscilar entre sofrimento e prazer ao longo de um mesmo dia, de uma mesma semana, de um mesmo ano. Alguns se sentem dolorosamente revoltados em face das desigualdades persistentes, outros sofrem quase permanentemente diante da impotência, perguntando-se cada 
manhã se vão "voltar para a escola". Alguns racionalizam a relação pedagógica, considerando o ensino como um trabalho "normal" e rotineiro, enquanto outros ainda vivenciam-no como uma aventura humana sempre apaixonante, seja pela inovação, movimentos pedagógicos, projetos ou simplesmente como uma forma de criatividade pessoal.

O sistema de ensino, por seu lado, está longe de apresentar efetivamente a homogeneidade que os textos sugerem. Van Zanten (200I) identifica uma "escola da periferia" que possui sua própria lógica. Em certas áreas deserdadas, parece que nos encontramos em um outro planeta, de tal forma se concentram os problemas, a falta de recursos, os profissionais mal formados. Uma relação constante é confirmada: os professores mais qualificados e experientes encontram-se, pelos mecanismos do tempo de serviço, nas regiões ou áreas mais "confortáveis", enquanto professores iniciantes ou eventuais são atirados à cova dos leões, o que aumenta os contrastes.

Quanto às normas e modelos pedagógicos, sucedem-se em tal ritmo após os anos 60, que se tornam uma espécie de bazar onde cada um compra o que quer, não obstante coexistam, no corpo docente, em geral no mesmo estabelecimento, "excelentes professores dos anos de 1930", segundo a fórmula irônica de um líder sindical, e professores muito "modernos", o que não quer dizer ipso facto eficazes.

De um sistema educacional relativamente imóvel, abalado por grandes reformas institucionais bastante espaçadas, passou-se a um sistema "em reforma permanente", seja nas estruturas, nos programas, nos procedimentos.

Pode-se tentar descrever tendências. Ao longo do século $X X$, passouse, progressivamente, no ensino primário (Perrenoud, 2002):

- de uma programação detalhada a indicações mais amplas, deixando mais autonomia aos professores;

- da idéia de que existe uma ordem única de progressão nos saberes à aceitação de rumos diversificados, correspondendo à diversidade das maneiras de aprender, dos estilos cognitivos, dos modos e dos níveis de desenvolvimento;

- da aparição de um saber em um só momento do curso, segundo o princípio "o que está feito está feito", às concepções ditas cíclicas ou "em espiral", as mesmas noções sendo trabalhadas e remanejadas várias vezes ao longo dos anos; 
- de grades horárias semanais estritas a prescrições de equilíbrios entre disciplinas a serem observados no decorrer do mês, do trimestre, de um ano escolar ou de um ciclo;

- da proposição de conteúdos a ensinar à especificação de objetivos de aprendizagem, o que dá ênfase às aquisições;

- de uma visão enciclopédica dos saberes a questões essenciais definidas como "objetivos-núcleos";

- de uma concepção estrita das disciplinas escolares a uma forma de pluridisciplinaridade;

- da prioridade dada aos conhecimentos à insistência sobre sua transferência e mobilização a serviço das competências;

- de objetivos de baixo nível taxonômico (memorização) a objetivos de alto nível (compreensão);

- de uma estruturação de curso em etapas anuais a uma estruturação em ciclos de aprendizagem plurianuais;

- da prescrição de um currículo imposto sem justificações a um currículo passível de ser lido, explicado aos alunos e aos pais e, numa certa medida, com estes negociado;

- de um currículo prescrito por experts (supervisores, formadores, às vezes pesquisadores) a um currículo elaborado ou aceito por uma base social mais ampla, incluindo uma parte dos professores;

- da prescrição de um currículo concebido sem nenhuma referência à avaliação dos alunos a tentativas de forte articulação às exigências, partindo do princípio de que a avaliação define "o verdadeiro programa", no entender dos alunos, dos pais e mesmo dos professores;

- de programas inteiramente estandardizados no interior de um sistema político à atribuição de uma certa "autonomia curricular" para estabelecimentos escolares;

- de um currículo prescrito estreitamente associado a documentos oficiais a um currículo que autoriza uma grande diversidade de meios de ensino, escolhidos livremente;

- de um currículo prescrito associado a métodos de ensino impostos ou fortemente recomendados a uma liberdade didática maior.

Mesmo se essas tendências, variáveis de um sistema a outro, possam ser confirmadas, nada permite afirmar que elas correspondam a uma mudança 
homogênea das práticas. Quem sabe, elas tenham provocado uma enorme "extensão do pelotão", como dizem os comentadores de uma corrida de ciclistas. As novas concepções curriculares autorizam práticas novas e audaciosas, em geral inspiradas nos movimentos pedagógicos ou na pesquisa em didática, mas permitem aos professores refratários não mudar grande coisa em sua maneira de ensinar, em razão da considerável margem de interpretação que o currículo oficial assegura ao professor, margem que aumenta do primeiro grau à universidade. Na sua maioria, os professores "utilizam ou ignoram-nas" segundo suas convicções, suas competências, sua energia. É possível, contudo, avançar a hipótese de que o currículo real traduz em certas turmas as idéias didáticas mais recentes e se aproxima, em outras, do que se ensinava no mesmo nível há vinte anos ou mais. Por isso é difícil saber se as reformas curriculares maiores em relação às matemáticas, às línguas maternas, às ciências humanas, ciências naturais, segunda língua, Educação Artística, Física ou Cívica, mudaram as práticas na mesma medida. Sem dúvida isso depende muito, entre outras coisas, da capacidade e da vontade bastante desigual dos estabelecimentos e dos professores de compreender, de aceitar e de colocar em ação o espírito desses textos.

Podemos manifestar as mesmas incertezas a propósito de outras dimensões de mudanças potenciais das práticas. Também nesse caso, as tendências podem ser relacionadas (Perrenoud, 2000), uma vez que as práticas pedagógicas:

- sustentam-se em objetivos de nível taxonômico cada vez mais elevado (por exemplo, aprender a aprender, a raciocinar, a comunicar);

- possuem cada vez mais a tarefa de construir competências, de não se ater aos saberes;

- recorrem cada vez mais aos métodos ativos e aos princípios da escola nova, às pedagogias baseadas em projeto, contrato, cooperação;

- exigem uma disciplina menos estrita, deixam mais liberdade aos alunos;

- manifestam maior respeito pelo aluno, sua lógica, seus ritmos, suas necessidades, seus direitos;

- atêm-se mais ao desenvolvimento da pessoa, menos a sua adaptação à sociedade;

- concentram-se mais sobre o aprendiz, sendo o professor concebido antes de tudo como organizador de situações de aprendizagem; 
- são mais sensíveis à pluralidade das culturas, menos etnocêntricas;

- tomam cada vez menos o fracasso escolar como uma fatalidade e evoluem no sentido da diferenciação do ensino como discriminação positiva;

- tendem a dissolver o conjunto estável da classe como única estrutura de trabalho, compondo grupos de trabalho, de projeto, de nível;

- são cada vez mais combinadas com outros intervenientes pedagógicos, no âmbito de um trabalho de cooperação;

- estão cada vez mais enquadradas no âmbito do estabelecimento ou voltadas para este;

- caminham para um planejamento didático cada vez mais flexível e negociado;

- dão cada vez mais lugar a tarefas abertas e a situações-problema;

- caminham no sentido de uma avaliação menos normativa e mais formativa;

- articulam-se mais facilmente com as práticas educativas dos pais, em favor de um diálogo mais equilibrado;

- tornam-se mais dependentes das tecnologias audiovisuais e informatizadas;

- deixam mais espaço para a manipulação, a observação e a experimentação;

- tendem a tornar-se reflexivas, sujeitas a uma avaliação e a um questionamento periódicos;

- levam mais em conta a pesquisa;

- mudam mais rápido; a inovação banaliza-se;

- são socialmente menos valorizadas, aparecem ao alcance de um número maior de pessoas instruídas;

- estão em processo de profissionalização, fundando-se nas competências adquiridas na formação inicial e contínua.

Aqui também essas disposições se manifestam muito desigualmente, tendendo a aumentar a heterogeneidade das práticas em razão da descentralização e da política dos projetos do estabelecimento, que permitiram experiências de vanguarda em certos lugares e derivações conservadoras em outros.

Que fazer em face dessa diversidade quando há que formular programas de formação inicial? Em outros setores, as escolas profissionais diversifi- 
cam-se e entram em concorrência. A coexistência de gêneros e estilos profissionais encontra um espelho ao menos parcial na gama das formações, que se distinguem não apenas por seus procedimentos, mas também por seus objetivos. Os psicoterapeutas, os atores, os artistas, os administradores são formados nas escolas que se singularizam expondo sua concepção do ofício. Cabe aos estudantes orientar-se nesse mercado de formação.

Quando a formação está sujeita a normas nacionais e não à livre concorrência, esse tipo de diversidade é proibido. Isso se torna ainda mais evidente quando se pretende, nos diversos estabelecimentos, incitar os profissionais a se integrarem a um "corpo profissional", cujos membros devem trabalhar sob forte normalização, em particular no âmbito da função pública. Mesmo fora da administração e em setores que escapam ao princípio de igualdade diante da lei, a tendência à estandardização dos diplomas em escala nacional, até mesmo continental, torna cada vez menos provável a coexistência a céu aberto de concepções muito diferentes do mesmo ofício. Se for preciso uma referência única, qual escolher e por quê? A questão será discutida aqui apenas do ponto de vista da cooperação profissional, mas ela se coloca nos mesmos termos a propósito de todas as dimensões do ofício.

\section{UMA FORMAÇÃO PROFISSIONAL PARA A COOPERAÇÃO}

Toda formação inicial de professores pretende preparar para uma ação profissional eficaz e pertinente, da qual não é possível ignorar ingenuamente os aspectos sistêmicos e coletivos. Sem dúvida é preciso ficar atento para não cair no equívoco de uma cultura de avaliação excessiva, que poderia levar as pessoas da escola até mesmo a rejeitar a idéia de eficácia, assimilada a indicadores contestáveis, a concorrências perversas ou a regulamentações neoliberais.

Além disso, a preocupação que compartilham os professores e os administradores quanto à eficiência da ação educativa é às vezes atenuada pelas preocupações muito centradas nos desafios pessoais e relacionais, e por isso insuficientemente orientada para a necessidade de desenvolver a qualidade da ação pedagógica junto aos alunos. Em relação a isso, as pesquisas internacionais recentes aplicaram um "choque elétrico" na maioria dos sistemas escolares. Ninguém hoje é capaz de negar: as condições de ensino e de aprendizagem devem ser bastante melhoradas se se quiser lutar de maneira mais efetiva 
contra um fracasso escolar que tende a persistir, apesar dos recursos investidos durante as décadas passadas. Por outro lado, os estudos comparativos recentes (Programa Internacional de acompanhamento das Aquisições dos Alunos - PISA -, por exemplo) confirmaram a importância do efeito-estabelecimento que dependeria, segundo pesquisas amplamente convergentes, das seguintes características:

- valores, representações e visões compartilhadas (inclusive pelos alunos), uma identidade e um perfil claramente explicitados (incluindo o foco na luta contra o fracasso escolar);

- focalização clara sobre as aprendizagens, junto com uma pedagogia diferenciada, uma avaliação formativa e uma aproximação de conteúdos que faça sentido para os alunos;

- organização do trabalho que corresponda aos objetivos visados (estruturas e agrupamentos flexíveis dos alunos, investimento do tempo necessário para realizar as tarefas prioritárias etc.);

- responsabilidade pelo êxito escolar de todos os alunos, compartilhada por todos os professores;

- estabilidade dos professores no estabelecimento, gerando a convicção da possibilidade de influir dissuadindo os professores de procurar fora da escola perspectivas menos deprimentes;

- referência explícita a um modelo teórico e a um sistema de indicadores confiáveis, constantemente verificados e atualizados, permitindo antecipar e controlar os efeitos dos dispositivos mobilizados sobre a aprendizagem dos alunos;

- atores coletivamente comprometidos com uma posição reflexiva, capazes de articular as dimensões conceituais e práticas, visando dominar o máximo possível os elementos que impedem atingir os objetivos de formação;

- diretores de estabelecimentos que saibam instaurar comunidades profissionais capazes de se envolver num processo contínuo de desenvolvimento (Hargreaves, 2003).

A eficácia nasce da sinergia dessas características, das configurações favoráveis que podem, em certos casos, abalar os paradigmas, transformar pro- 
funda e completamente as representações do ofício e das práticas pedagógicas e, por isso, produzir efeitos consideráveis junto aos alunos. Mas falar não é suficiente, é preciso criar as condições necessárias para tornar possível essa evolução, em todos os níveis do sistema, adaptando em conseqüência os dispositivos de formação inicial e contínua.

Em que consistiria uma formação profissional para a cooperação de acordo com essas características? Retenhamos os seguintes aspectos:

- ter consciência de que a cooperação não é elemento dominante da profissionalização de professor;

- não confundir cooperação com afinidades eletivas;

- manter uma relação utilitarista e seletiva com a cooperação;

- apropriar-se dos instrumentos psicossociológicos, éticos e jurídicos pertinentes;

- aprender a enfrentar as crises, os conflitos, os não-ditos e a regular a ação coletiva;

- aprender pela prática a funcionar em vários registros.

Esses elementos são em parte passíveis de ser transpostos para outras dimensões do ofício. Limitemo-nos aqui a desenvolvê-los um pouco tendo em vista a cooperação.

\section{A cooperação não é elemento dominante da profissionalização de professor}

Os observadores sabem que o individualismo é a figura dominante do ofício de professor. Mas e os professores em formação, sabem disso? Ora, se eles fizerem vários estágios em estabelecimentos diferentes, verificarão que, entre o discurso que apresenta a cooperação como algo natural e as práticas, existe um fosso. Entretanto, essa experiência da diversidade não é suficiente. Ela resulta geralmente em um posicionamento normativo. Os estudantes-estagiários mais cooperativos distanciam-se dos "individualistas inveterados" que encontram no caminho e sonham "cair" num estabelecimento que contenha poucos "combatentes solitários". Os estagiários mais individualistas sentem-se reconfortados ao ver que aquilo que alguns formadores Ihes apresentaram como uma evidência - trabalhar em grupo - é apenas uma imagem entre ou- 
tras do ensino; eles se alegram de ver que existem ainda escolas sem equipes, sem projeto, onde eles têm uma chance de praticar o ensino que sonharam: único mestre em face dos alunos, a portas fechadas.

Constatar a diversidade das relações de cooperação não é suficiente. É importante que na formação inicial essas representações sejam trabalhadas explicitamente, segundo dois eixos:

- compreender que o individualismo não é somente "uma questão de caráter", que está ligado paradoxalmente a uma cultura comum, à história da profissão e, sobretudo, às condições da ação de ensinar e à solidão de cada um no registro dos saberes para ensinar e das convicções íntimas, sejam elas éticas, didáticas, ou epistemológicas;

- trabalhar sua relação pessoal com a cooperação, sua visão própria da profissão, sua relação com o poder, com os outros, com o controle, com a competição e a solidariedade.

Chegamos agora à pessoa e a sua relação consigo e com os outros. É preciso evidentemente encontrar procedimentos e dispositivos adequados de formação.

\section{Não confundir cooperação com afinidades eletivas}

Saber cooperar com uma determinada pessoa que você escolheu e que o escolheu, é melhor que nada, mas o modo de gestão do corpo docente torna improvável tal situação. Mesmo algumas exceções à regra mostram que a cooptação só raramente é uma solução garantida, pois os atores envolvidos tendem freqüentemente a esquecer que um sistema é mais do que a soma de suas partes, que a introdução de um novo elo numa rede de relações vai destruir antigos equilíbrios, em geral arduamente atingidos, e que será preciso investir uma grande energia para renegociar novos acordos, elaborar novas maneiras de fazer, levar em conta as necessidades de cada um. Os limites da cooptação têm a ver com a fragilidade de todo sistema humano, com suas esperanças, suas tensões, seus conflitos de poder, de idéias e de interesses.

A essa dificuldade se junta uma outra: nenhum processo de envolvimento, por mais sofisticado que seja, dará garantia total quanto às atitudes e com- 
petências dos novos integrantes, tendo em vista sua compatibilidade com o funcionamento da equipe na qual eles se inserem. Daí a importância de uma forma de contrato social que obrigue todas as partes envolvidas a fazer um esforço para elaborar um modus vivendi que, por um lado, levará em consideração as orientações dadas pelos veteranos e, por outro lado, permitirá aos novos encontrar seu lugar e questionar as certezas dos professores mais antigos.

\section{Manter uma relação utilitarista e seletiva com a cooperação}

Cooperar não é um valor em si, é apenas um modo de fazer melhor o trabalho. Saber cooperar, é talvez, antes de mais nada, "saber não cooperar quando não for necessário!” (Gather Thurler, 1996). Se, para se furtar a toda suspeita de individualismo, ninguém ousa tomar decisão nem tomar qualquer atitude sem pedir a opinião dos colegas, corre-se o risco de caminhar para a paralisia e preparar efetivamente o retorno ao individualismo de professores que se sentem asfixiados pela cooperação invasiva. Esse sentimento de asfixia se desenvolve muito rapidamente e como tal mereceria tornar-se objeto de formação: o ofício de professor parece engendrar (ou privilegiar, dependendo da orientação) uma fraca tolerância em relação aos compromissos vivenciados com outros adultos.

Nas culturas de cooperação profissional orientadas para a mudança, a prioridade é dada "à problematização dos dilemas profissionais e à resolução de problemas pedagógicos". Não há, de início, um esforço para "tornar-se uma equipe"; os procedimentos não priorizam nem o "bem-estar" de cada um nem o funcionamento da equipe, pois a equipe e o trabalho de equipe não se "situam no mesmo nível de preocupação". É sem dúvida importante submeter tanto o funcionamento quanto o bem-estar de cada integrante da equipe a uma avaliação, para evitar desvios e para introduzir, em caso de fracasso, os ajustes necessários. Dar prioridade à cooperação impede, entretanto, o desenvolvimento dos conteúdos, leva o coletivo a "voltar-se para o próprio umbigo" e pode tornar-se realmente paralisante.

De fato, é importante levar os futuros professores a desconstruir toda representação "romântica" da cooperação profissional, fazendo-os tomar consciência de que esta é com freqüência o resultado de uma longa evolução, marcada por numerosos problemas de comunicação, conflitos de poder e de 
interesses. E que ela só é possível pela vontade explícita e insistente de uma equipe de professores que busca orientar o essencial de sua trajetória rumo a um objetivo comum; que visa ao alargamento das competências individuais e coletivas para assegurar o sucesso dos alunos; que leva os sujeitos a se perceberem, enquanto indivíduos, como um elo importante do sistema, participando ativamente de seu desenvolvimento.

\section{Apropriar-se dos instrumentos psicossociológicos, éticos e jurídicos}

funcionamento de uma equipe ou as relações de cooperação não são realidades indizíveis e opacas. A análise não resolve tudo, mas permite tomar distância, não interpretar o que ocorre apenas em termos normativos e afetivos, não ter que escolher entre assumir tudo sozinho ou jogar tudo para o outro. Essa análise pode sustentar-se em três registros de saberes e de reflexão.

As ciências sociais e humanas, da etologia à sociologia, passando pela psicanálise, psicologia social, psicossociologia, ergonomia, acumularam um certo número de conhecimentos sobre a cooperação, a formação e a dinâmica de grupos restritos, sobre os processos de influência, de decisão, de segregação, de controle social, de concorrência, de exclusão, de conflito, sobre os fenômenos de liderança e de conformismo, enfim, sobre as relações entre o indivíduo e o grupo. Apropriar-se de uma parte desses saberes tornaria os professores menos ingênuos e, portanto, menos vulneráveis diante do inconsciente, do poder, da complexidade das relações humanas e da vida nas organizações.

A ética está implicada nas relações com os alunos e seus pais, mas também nas relações com os colegas. Mesmo quando trabalha sozinho, um professor pode ser chamado a ajudar ou pode ele próprio oferecer-se para tanto. Ele pode estar envolvido em uma luta de "tribos" ou em tentativas de sedução ou de perseguição por colegas. Mesmo um individualista tem necessidade de uma ética da relação, já que ele não vive em uma ilha deserta. Ela é ainda mais necessária numa equipe, em relação à solidariedade, ao segredo, ao respeito e à autonomia de cada um, à partilha das informações e dos recursos, às relações de cada um com os alunos, que não hesitam em jogar os professores uns contra os outros. Por definição, a ética não é um sistema de regras, mas ela permite refletir, orientar-se, enfrentar os dilemas comuns, ou peculiares. 
O direito é o grande ausente da formação dos professores. Talvez recebam alguma iniciação sobre a legislação que rege a educação nacional: os programas, o regulamento das escolas, as sanções, os direitos e deveres do funcionário etc. A cooperação apresenta problemas de uma outra ordem: propriedade intelectual, responsabilidade coletiva, segredo profissional, delegação de poder de animar ou de representar uma equipe, regulação dos litígios, direito de excluir um elemento da equipe ou de recusar uma adesão.

\section{Aprender a enfrentar crises, conflitos, não-ditos e a regular a ação coletiva}

Os sistemas de ensino absorveram a idéia de que é preciso dar certa autonomia aos estabelecimentos escolares e, em conseqüência, dar a estes a autonomia de definir, no interior de um quadro definido, seu próprio projeto. Ao mesmo tempo, as sociedades modernas perceberam que seria preciso pôr fim ao mito da objetividade absoluta, cessar de acreditar que os sistemas de ação evoluem segundo leis perfeitamente racionais. Diante dos dilemas profissionais, não existe jamais uma só resposta defensável. Obrigados a agir com urgência justamente quando eles precisariam de tempo para decidir com conhecimento de causa, constantemente expostos a solicitações de toda parte, os professores acabam por ver-se na obrigação de negociar acordos sem os quais não podem se comprometer com uma ação coletiva eficaz.

Ora, esse processo de construção é difícil: raramente se desenvolve sem crise; as partes interessadas terminam envolvidas em conflitos em que o resultado nem sempre é salutar. Diante dessa realidade - incontornável, por ser inerente a toda coletividade, obrigada a pôr em funcionamento suas práticas e modos de pensar a fim de responder às demandas sempre mais exigentes de seu entorno - muitos professores ficam desarmados, pois eles não possuem nenhuma "cultura do conflito". Desagregam-se tão logo os desacordos se fazem sentir, não aceitando que se questionem suas certezas; têm medo que o grupo se desfaça e preferem permanecer no não-dito em lugar de apontar os problemas de funcionamento.

É, pois, importante desenvolver junto aos futuros professores as competências indispensáveis para que eles afrontem a cooperação profissional com conhecimento de causa, armados de um certo número de conceitos e de ferramentas para fazer evoluir favoravelmente a dinâmica de grupo, para apren- 
der a administrar as emoções que vão junto com cada aventura coletiva (Hargreaves, 2002, 2002a).

\section{Aprender pela prática a funcionar em vários registros}

Como esperar que os estudantes aprendam a cooperar se, durante seus estudos, são incentivados ao máximo de individualismo mediante os concursos, as formas de avaliação, os percursos de formação? Como esperar que eles possam por sua vez formar seus alunos para a cooperação, se não lhes é oferecida a ocasião para fazer a experiência e adquirir competências durante sua formação?

Seria interessante ver até onde e por quais meios as instituições de formação chegam realmente a desenvolver em seus estudantes as competências que necessitarão para:

- cooperar em registros e com parceiros muito diferentes, sem se desagregar diante do primeiro obstáculo encontrado;

- identificar as modalidades de cooperação mais bem adaptadas a diversos tipos de situação - discernir quando cooperar sobrecarrega o trabalho sem proveito e quando, ao contrário, é uma condição que propicia maior eficácia;

- saber rapidamente situar os modos de cooperação e de resistência que prevalecem num estabelecimento, de maneira a poder ocupar seu lugar, sem renegar suas convicções, mas também sem provocar reações de hostilidade ou de ironia, que só levam a regressão para um conformismo em relação às normas ambientes.

\section{E A COOPERAÇÃO ENTRE FORMADORES?}

"Faça como eu digo, mas não faça como eu faço ": quem ousaria acreditar nos efeitos de uma formação sustentada por tal postura? Ao mesmo tempo, a estrutura das instituições universitárias de formação de professores não é feita para favorecer uma cooperação profissional de alto nível. A divisão do trabalho ao extremo, a grade horária, um individualismo reforçado pelos modos de gestão das carreiras, a primazia das divergências epistemológicas e te- 
óricas são apenas alguns elementos dentre outros que fazem pensar que poucas ocasiões são oferecidas aos estudantes de vivenciar, durante seu percurso de formação, aquilo que se exige deles. Paradoxalmente, as equipes universitárias mais convincentes são as equipes de pesquisa, menos visíveis para os estudantes.

Quando existem verdadeiras equipes de formação, o pudor ou a prudência impedem os formadores de erigi-las em exemplo, de estampar seu próprio modo de cooperação para instar os estudantes a identificar os aspectos favoráveis e as dificuldades do trabalho em equipe. Os estudantes não são cegos, o individualismo dos formadores não Ihes escapa, nem a contradição entre suas práticas e seus discursos. Entretanto, suas críticas são raramente suficientemente agudas para ultrapassar o senso comum e situar os formadores diante de suas contradições. Estes, salvo se suas virtudes ou sua militância, venham dissuadi-los, seguirão a lógica da instituição. Chega-se aí a uma questão maior: se as universidades ocupam-se da formação profissional, seria desejável que elas aprendessem a funcionar diferentemente quanto ao registro da cooperação... e quanto a outras coisas mais...

\section{REFERÊNCIAS BIBLIOGRÁFICAS}

AMADIEU, J.-F. Organisations et travail: coopération, conflit et marchandage. Paris: Vuibert, 1993.

AUDUC, J.-L. Agir en équipe. Créteil: CRDP, 1998.

BARRÈRE, A. Les Enseignants au travail: routines incertaines. Paris: L'Harmattan, 2002.

Pourquoi les enseignants ne travaillent-ils pas en équipe? Sociologie du travail, n.44, p.48I-497, 2002a.

BLANCHARD-LAVILLE, C. Les Enseignants entre plaisir et souffrance. Paris: PUF, 200 I.

BRONCKART, J.-P.; GATHER THURLER, M. (dir.) Transformer l'école. Bruxelles: De Boeck, 2004. (Coll. Raisons Educatives)

CORDONNIER, L. Coopération et réciprocité. Paris: PUF, 1997.

GATHER THURLER, M. Coopérer dans les équipes de cycles. Vie Pédagogique, n. II4, p.27-30, févr./mars 2000. 
Coopérer efficacement: difficile mais possible. Éducateur, n. 12/17, p. $17-$ 22, oct. 1997.

Les Cycles pluriannuels et leur impact sur le travail des enseignants. In: BIRON, D.; CIVIDINI, M.; DESBIENS, J.-F. (dir.) La Profession enseignante au temps des reformes. Sherbrooke: Éditions du CRP, 2004. p.459-476.

Innovation et coopération entre enseignants: liens et limites. In: BONAMI, M.; GARANT, M. (dir) Systèmes scolaires et pilotage de l'innovation: émergence et implantation du changement. Bruxelles: de Boeck, 1996. p. I45-168.

L'Innovation négociée: une porte étroite. Revue Française de Pédagogie, n. 130, p.29-43, janv./mars 2000a.

. Innover au coeur de l'établissement scolaire. Paris: ESF, 2000b.

Mobilisation et compétences au sein d'une équipe pédagogique: savoir pour vouloir. Éducateur, n. 10, p. 15-19, 26 sept. 1999.

Stratégies d'innovation et place des acteurs. In: BRONCKART, J.-P.; GATHER THURLER, M. (dir.) Transformerl'école. Bruxelles: De Boeck, 2004. p.99- I25. (Coll. Raisons Educatives)

HARGREAVES, A. The Emotional geographies of teachers' relations with colleagues. International Journal of Educational Research, n.35, p.503-527, 2002.

. Teaching and betrayal. Teachers and Teaching: Theory and Practice, v.8, n.3/4, p.393-407, 2002a.

. Teaching in the knowledge society: education in the age of insecurity. New York: Teachers College Press and Buckingham: Open University Press, 2003.

MAHIEU, P. Travailler en équipe. Paris: Hachette, 1992.

PERRENOUD, P. Les Conceptions changeantes du curriculum prescrit: hypothèses. Éducateur, n. I, p. 48-52, 2002. (Numéro spécial: Un siècle d'éducation en Suisse romande)

Les Cycles d'apprentissage: une autre organisation du travail pour combattre l'échec scolaire. Sainte-Foy: Presses de l'Université du Québec, 2002a. chap. 10, 1 I

Dix nouvelles compétences pour enseigner: invitation au voyage. Paris: ESF, 1999. Travailler en équipe: chap. 5

Pouvoir et travail en équipe. In: CHUV Travailler ensemble, soigner ensemble. Actes du symposium. Lausanne: CHUV, Direction des soins infirmiers, 1996. p. 19-39. 
Les Pratiques pédagogiques changent-elles et dans quel sens? Pour: Revue de la Fédération Syndicale Unitaire. Paris, n.65, p. I4, mai 2000.

Réfléchir ou agir ensemble? Éducateur, n. 12, p.8-1।, 17 oct. 1997.

Travailler en équipe pédagogique, c'est partager sa part de folie. Cahiers pédagogiques, n.325, p.68-7I, juin 1994.

RANJARD, P. L'Individualisme, un suicide culturel:les enjeux de I'éducation. Paris: L'Harmattan, 1997.

SPRENGER, R. K. Mythos Motivation: Wege aus einer Sackgasse. Frankfurt: Campus, 1992. TERSSAC, G. de. Autonomie dans le travail. Paris: PUF, 1992.

TERSSAC, G. DE; FRIEDBERG, E. (dir.) Conception et coopération. Toulouse: Octarès, 1995.

ST.-ARNAUD, Y.L'Interaction professionnelle: efficacité et coopération. Montréal: Les Presses de L'Université de Montréal, 1995.

VAN ZANTEN, A. L'École de la périphérie: scolarité et ségrégation en banlieue. Paris: PUF, 2001 .

Recebido em: fevereiro 2006

Aprovado para publicação em: março 2006 